\title{
¿QUÉ SOMOS? ¿QUÉ FUIMOS?
}

\section{WHAT ARE WE? WHAT WERE WE?}

José Antonio Martínez Pons: Departamento de Química Analítica e Ingeniería Química. Universidad de Alcalá de Henares. Madrid (España) joseantonio.martines@uah.es

\section{CURRÍCULUM VITAE}

Licenciado en Ciencias Físicas (Geofísica) por la Universidad Complutense de Madrid (España) y en Ciencias Químicas (Química Física) por la UNED (España). Doctor por la Universidad de Alcalá de Henares (España) en el año 2000. Profesor de la Universidad de Alcalá de Henares en el área de Química Analítica e Ingeniería Química.

\section{RESUMEN}

En esta ocasión conviene recordar a San Agustín, que dijo: si me preguntan si sé lo que es, lo sé; si me preguntan que lo explique, no sé explicarlo. Todos nos definimos como universitarios, pero detrás de este término se esconden muchos siglos de historia, desde la Edad Media cuando surgió la institución universitaria. En este artículo se lleva a cabo una reflexión sobre ello.

\section{PALABRAS CLAVE}

Universitarios - Edad Media - Estudios 


\section{ABSTRACT}

On this occasion should recall St. Augustine, who said, if you ask me if I know what it is, I know, if you ask me to explain it, I can't explain it. All we define ourselves as academics, but behind this term conceals many centuries of history from the Middle Ages came the university. This article performs a reflection about it.

\section{KEY WORDS}

Academic people - Middle Ages - Studies

TEXTO:

Cuando se nos pregunta que nos definamos estoy seguro que el apelativo más común y con el que todos nos sentimos de acuerdo es el de "universitarios". El epíteto acoge desde al estudiante recién ingresado, hasta al catedrático emérito, o al rector más emperifollado.

Una definición del término es difícil. Una vez más conviene recordar a San Agustín: "si me preguntan si sé lo que es, lo sé. Si me preguntan que lo explique, no sé explicarlo". O tal vez a Don Julio Palacios, del que se cuenta afirmaba que toda definición acababa en una petición de principio, y daba ejemplo con su famosa definición de temperatura: "es lo que mide un termómetro". Realmente tras el adjetivo o sustantivo de "universitario" se esconden muchos siglos de historia; como tras el nombre de Universidad se esconden muchas realidades. Por mucho que ahora se empeñen en lo contrario, no será nunca el mismo concepto de Universidad el que tienen los norteamericanos que el que tienen los alemanes, ni el que tienen los 
británicos del que tenemos los latinos. Sin embargo, hay un denominador común en todas las universidades, en todas ellas se buscan tres cosas, al menos sobre el papel: La sabiduría, entendida en su sentido más amplio, la investigación y la formación de futuros intelectuales. Muchas veces la formación viene acompañada, superadas una serie de pruebas, de la concesión de un título que, en general, faculta para un determinado ejercicio profesional.

El origen de la institución universitaria se pierde en las brumas de la Edad Media, no es ahora el momento de hacer un ejercicio de erudición histórica. Sí parece claro que las universidades derivaban de las antiguas escuelas monacales y que, durante mucho tiempo, en Europa, buena parte del profesorado pertenecía al estamento clerical, secular o regular. Es curioso que, por ejemplo, en la Sorbona, consta que los estudiantes preferían a los regulares porque acudían a clase todos los días y sin "resacas" de buenas cenas y otras actividades no precisamente "sanctas", que eso del celibato eclesiástico de "iure" data, más o menos, del Papa Gregorio VII, el "terrible" monje Hildebrando; de "facto" corramos un tupido velo, quizás se limite al siglo XX (¿quién no conoce a alguien apellidado "del Cura"). Es curioso que existe una carta de los obispos alemanes al Papa tildándole de meretriz del Apocalipsis y acusándole, parafraseando las invectivas de Jesús a los fariseos, de imponer a los demás cargas que él no puede llevar, en clara referencia a la condesa Matilde, aunque no hay prueba alguna sobre el fundamento real de tales alusiones, entre otras razones debido a la edad del Papa en cuestión. De lo que no hay duda es que san Gregorio era un hombre de carácter y de ideas claras.

Resumiendo, y perdón por mi pequeña digresión pseudo histórica, en la edad Media las universidades agrupaban sus enseñanzas en cuatro facultades: Artes, Leyes y Cánones, Medicina y Teología, aunque después las universidades destacaran en una u otra disciplina, por ejemplo: Salamanca, Bolonia o Aviñón destacaban el Leyes, 
Montpelier en Medicina, París en Teología y Oxford y Cambridge en Lógica y Filosofía.

No hay que creer que, pese a sus reminiscencias monacales, la vida universitaria era plácida. No, la universidad era un hervidero de inquietud intelectual, de acuerdo con los saberes de su tiempo, donde la innovación y el inmovilismo estaban en constante pugna, llegándose a algaradas que mantuvieron, por ejemplo, cerrada la Universidad de París. Eran las disputas entre platónicos, los "carcas" y aristotélicos, los "progres", y los trucos y las reservas mentales de ciertos profesores, como dar la primera clase explicando a Platón, anunciar, a continuación, la falsedad de lo explicado, pasarse el curso con Aristóteles y acabar reivindicando a Platón; táctica que se prohibió, por supuesto, aunque al final Aristóteles se llevó al gato al agua; loor sea dado al "divino Tomás" y de rebote a nuestro Patrón, san Alberto, y vuelvo a perderme en mis recuerdos de adolescencia -y alguien pretenderá comparar mi Bachillerato, plan 57, con los remedos que se enseñan ahora-.

Volvamos a la universidad en general ¿Cómo era la vida académica entonces?

Los adolescentes solían ingresar en la Universidad a los quince o dieciséis años, aunque no era infrecuente que personas mayores, sobre todo clérigos se dejaran ver por las aulas -por supuesto, varones-. Todo estaba muy reglamentado, como corresponde a la mentalidad medieval. Los cursos eran largos, solían empezar en octubre y se prolongaban casi hasta septiembre. Como no había muchos libros y los pocos que había eran muy caros, la enseñanza era fundamentalmente oral. Las clases, que se impartían en latín, solían empezar a las seis o siete de la mañana y se iniciaban con la lectura de un texto por parte del maestro, "lectio". A la lectura seguía el comentario, "comentatio", y a eso de las nueve la disputa entre maestro y estudiantes, "disputatio", y las repeticiones del texto para que los estudiante los memorizaran. La 
primera sesión solía acabar a la hora de comer y por la tarde había otra sesión, con el mismo patrón. De tres a cinco lectio y después repeticiones y disputas.

Los estudios se iniciaban en las facultades de Artes donde el universitario estudiaba las artes liberales: el trivium (gramática, dialéctica y retórica) y el cuadrivium (aritmética, geometría, astronomía y música). Cumplidos los años preceptivos, se estaba en condiciones de ingresar en alguna de las facultades mayores, cuya permanencia "activa" también estaba estrictamente regulada -Cuatro años para Medicina, cinco para Teología y seis para Leyes, por ejemplo-. Superados los años de escuchar lecciones, el estudiante estaba en condiciones de optar al grado de Bachiller.

Para obtener el grado, el estudiante elegía un doctor de su facultad para que se lo confiriera e informaba al rector de que cumplía los requisitos de conocimientos cursos y lecciones. Hecho esto, en un día normal de clase, tras anuncio del bedel, el candidato subía a la cátedra y pronunciaba una arenga en la que solicitaba la concesión del grado. El padrino concedía el grado y el neobachiller volvía la cátedra, donde, tras solicitar el auxilio divino, pronunciaba una breve lección. Después debía abonar las pertinentes tasas a bedel, notario y rector e invitar a sus amigos a un banquete.

Obtenido el grado, se podía aspirar a la licencia docendi, nuevo grado que confería la facultad de enseñar. Para ello eran necesarios más años de estudio -cuatro en Medicina, Derecho o Teología y tres en Artes-, durante los cuales el candidato debía "leer" públicamente.

Obtener el título era más complicado. Primero había que comprobar que el candidato reunía las condiciones precisas. Superados estos trámites, el doctor más antiguo de la facultad debía presentar la candidatura. Aceptada ésta se fijaba un día. Los actos comenzaban con una misa del Espíritu Santo. Después se reunían solemnemente los 
doctores de la facultad y se efectuaba un sorteo sobre la materia sobre la que debía disertar el candidato. Éste preparaba la exposición y, al día siguiente, la defendía públicamente. Oída la disertación, los doctores, mediante voto secreto, decidían si merecía o no el grado. Si era aprobado, venía un nueva investigación para determinar si había habido sobornos $\mathrm{y}$, en caso de que todos los pronunciamientos fueran favorables, previo pago de nuevas gabelas, se le concedía la ansiada licentia docendi. El doctorado no añadía nuevas prebendas al licenciado y consistía en la imposición de las insignias de maestro. No obstante, los costes de todo el conjunto de actos y ceremonias eran muy elevados, de modo que quedaba fuera del alcance de muchos estudiantes.

La vida universitaria no cambió en exceso en el Renacimiento, ni siquiera en el Siglo de Oro, basta leer las joyas de la picaresca, en especial el Buscón.

Es curioso que hasta la vestimenta de los estudiantes y maestros estaba reglamentada. Un gracioso ejemplo es el coro de estudiantes del Barberillo de Lavapiés, zarzuela de Francisco Asenjo Barbieri, ambientada en tiempos de Floridablanca.

Cantan los estudiantes:

-A pedir venimos de Alcalá de Henares que las faldas quiten a los estudiantes, pues, si son traviesos y si son audaces, es por llevar faldas como las comadres.... etc. (recomiendo muy encarecidamente la escucha de esta zarzuela, de verdad que vale la pena).

Los que ya peinamos canas, recordamos a los seminaristas con sus becas azules o rojas y todavía hoy, en nuestras universidades, se luce el traje académico en los actos solemnes. En Italia aún hoy los estudiantes suelen lucir un curioso sombrero 
parecido al típico de Pinocho y, hasta hace muy poco, los aspirantes a clérigo estudiantes del Colegio Alemán de Roma vestían un sotana color rojo bermellón con faja negra, que les impuso el fundador del Centro, San Ignacio de Loyola, con la sana idea de hacer que los germánicos trasplantados al mundo mediterráneo, se contuvieran antes de abusar del vino y de las amables romanas.

No hay que olvidar que, desde siempre, los estudiantes se distinguieron por sus travesuras. Muchos de ellos subsistían gracias a la "sopa" conventual, de ahí el dicho de sopista o "estudiante de la sopa" que se dice en los países catalanes. Otros se ganaban la vida cantando -ése es el origen de nuestras tunas-. En resumen, una vida, en muchos casos, bastante a salto de mata.

La verdad es que después de un buen rato de darle a la tecla no sé donde he acabado..., quizás en una pregunta:

¿En verdad han cambiado mucho las cosas, las buenas y las malas, en siete u ocho siglos?

Mucho me temo que no y no creo que haya que lamentarlo demasiado.

Gaudeamius igitur iuvenes dum sumus....

Quizás lo que debería definir la Universidad es esta juventud permanente, este afán por conocer cosas nuevas, ese buscar siempre y que cada hallazgo nos muestre el horizonte un poco más lejos, porque, mientras la ciencia a descubrir no alcance la fuentes de la vida, habrá poesía y la vida sin poesía sería muy incompleta. 
Nota el pie: Pido disculpas a mis eruditos colegas de Historia y ciencias afines. Uno es de Ciencias desde su más tierna infancia y mis citas en este pequeño..., no sé cómo llamarlo, son todas de memoria, incluso los latinajos. 